\title{
The Methods Used in the Automotive Production: Hemming Operations Planning
}

\author{
Sezgin Ersoy, Ishak Ertugrul, Ebuzer Aygul \\ Mechatronics Department, Technology Faculty, Marmara University, Istanbul, Turkey \\ Email address: \\ sersoy@marmara.edu.tr (S. Ersoy), ishak.ertugrul@marmara.edu.tr (I. Ertugrul), ebuzer.aygul@marmara.edu.tr (E. Aygul) \\ To cite this article: \\ Sezgin Ersoy, Ishak Ertugrul, Ebuzer Aygul. The Methods Used in the Automotive Production: Hemming Operations Planning. Engineering \\ and Applied Sciences. Vol. 2, No. 6, 2017, pp. 103-106. doi: 10.11648/j.eas.20170206.12
}

Received: February 28, 2017; Accepted: April 15, 2017; Published: January 10, 2018

\begin{abstract}
Hemming is a method used to combine the metal-based parts in automotive manufacturing. Generally, this method is using as an assembly method for closures as doors, hoods, tailgates and trunk lids in automotive bodies. A compound flanging and hemming die is mounted on a carriage for horizontal movement into and out of alignment with the anvil for successive formation of a flange and impacting the flange into a finished hem. In this work aim is explain to Hemming methods and devices and their planning for manufacturing.
\end{abstract}

Keywords: Automotive Parts, Timing, Planning

\section{Introduction}

Hemming is widely used in the automotive manufacturing industry to assemble an outer closure panel and an inner closure panel by folding the flange of the outer panel over the edge of the inner panel $[1,2]$. This process is performed by material suffered a plastic deformation. Neat and compact combination of these methods that do not show up to join the resistance welding. Sometimes used special adhesives to improve strength.

The purpose of Hemming projects is to fold and fold the outer sheet metal panels on the inner sheet metal panels in various parts, such as the vehicle's door, engine hood, trunk lid, usually composed of two sheet metal panels, and to join the two panels together.

E. R. St. Denis \& Sons, Limited [3] advanced hemming machine for the joining of two preformed metal plates. Especially, the current work be attached to a machine for structure car doors. Furthermore, this work contact to a machine and a way for building a unitary construction from a first steel plate having a raised flange and a second steel panel having a straight edge section.

Sid Michaels and Pedro T. Silva [4] developed a device and process for automatically folding and stitching both tubular-shaped clothes. Tubular shaped clothes parts are mostly completed with an edge in which the raw edge of the cloth is twisted over either in a single fold or double fold and a peripheral stitch is sewn through the fold to create the edge. Michel Letard and Daniel Renouvin [5] designed a component to use in combination with a sewing machine which could be used for hemming out the loose end of tubular portions of garments. Their device consisted of a guide cylinder with a stop and retractable tension cylinder mounted on the sewing machine. Compressed air was used for the removal of garment from the device.

Hemming different technologies used in the automotive industry. These levels of investment, process time, as the technical requirements can be distinguished according to various factors. [6-8]

This study will examine the main stages of a suitable robotic roller hemming process as claimed in one of the production capacity on an annual basis. Process inputs used in the process of development is predictive.

\section{Hemming Stages}

\subsection{Before Hemming}

The production process of a system starts with the method of deep tensile on the press lines of its components. After the component is formed on the press lines, the outer sheet is crimped to the edges to be hemming. This process is called 
flanging. During the flange-forming phase, the edges are bent to be near or equal to $90^{\circ}$. Fig. 1 shows the production of the automobile part in the deep tensile die and trimming the resulting part by the trim process [9].
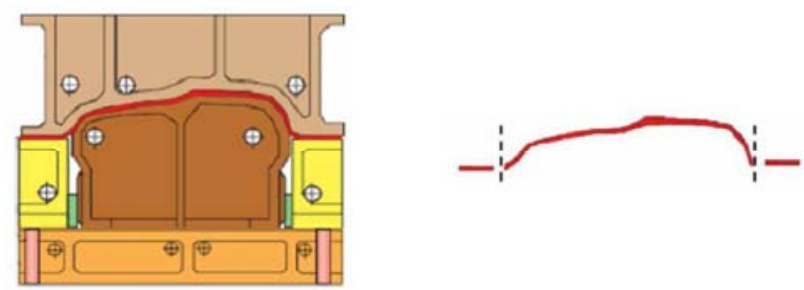

Figure 1. Production of automobile part in deep tensile mold [9].

\subsection{Bonding Process}

Bonding is the joining process by applying adhesive to the inner panel or the outer panel in various chemical properties before joining by hemming method. Adhesive material is applied before marriage process. Areas to be applied with adhesive can be applied pointwise or linearly according to the process needs. The linear application of the adhesive along the hemming line is called a "hemming bond". The hemming bond generally remains within the curved edges. Its application in the point is called "antiflutter" and its application to the middle parts of the inner and outer sheet helps to eliminate the sound problems caused by vibration.

The purpose of the bonding process is strengthening the consolidation process, prevent corrosion problems by providing tightness and during the use of the vehicle, the parts joined by the hemming method are to be insulated against vibrating voices due to the gap left between them. [10-13].

\subsection{Marriage Process}

The marriage process is to bond the inner sheet and outer sheet together after bonding. The marriage process can be done by the operator or by robotics. Depending on the need of the process, additional spot welding can be done after the marriage process. After completing the marriage process, it goes to the hemming phase [10-13].
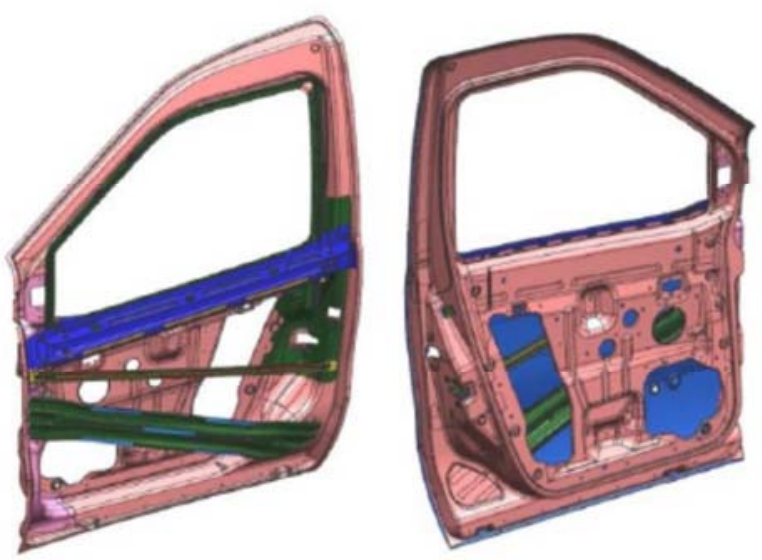

Figure 2. The inner and outer panel pairs of a vehicle door combined with the Marriage Process method [9].

\section{Hemming Methods}

Different hemming technologies are used in the automotive sector. these are distinguished by various factors such as investment level, process, time, technical requirements.

\subsection{Die Hemming Method}

It is the oldest automatic hemming method. the bend is made by press force. Hemming is performed in two steps: Pre-hemming and Final-hemming. Hemming can be done faster with this method, so it is suitable for high volume production $[9,14]$.

\subsection{Table Top Hemming Method}

It is a method of hemming using a table-top mold specially designed for the product to be fully produced. the bend is made by press force. the process is done in two steps, prehemming and final hemming $[9,14]$.

\subsection{Robotic Roller Hemming Method}

Robotic Roller Hemming method is a method which is not similar to other methods, is accompanied by a cylinder mechanism operating in a circular motion on the 6th axis of an industrial robot. Robotic roller in hemming application, cylinder mechanisms are used at different diameters according to process needs. These are called hemming heads. Hemming heads can be purchased as standard or specially designed according to process requirements. The geometric differences of hemming heads have an effect on the bending process. Hemming heads should be designed and manufactured in the form of corner of the part to be hemmed, differently from the form of the twist, or supplied from suppliers on the market according to their suitability [9].

The maximum roller hemming speed to be considered when performing the process time analysis in robotic roller hemming applications should be $150-200 \mathrm{~mm}$ / sec according to the part geometry. As an example, consider the hemming rate of a vehicle's engine hood:

Engine bonnet predictive hemming length: $5500 \mathrm{~mm}$ accept;

The hemming time is found at $\mathrm{t}=4500 / 150=30$ seconds for 1 st order.

The total hemming time for all transactions completed on 3rd order: $\mathrm{t}=5500 / 150 * 3=90$ seconds.

Robotic roller hemming is a relatively new method and there is very limited documentation and know-how about the process. Achieving and maintaining the right product quality is possible through a number of trial and error processes. Finite element analysis (FEA) helps to shorten the trial and error process of the robotic roller hemming process $[9,10$, 14].

It is aimed to create a more stable process and product quality. The main objectives are to determine the rules of a process that can provide size and surface quality and shorten the process time. These targets can be captured by constructing a three-dimensional finite element analysis 
(FEA) model.

Theoretically, in terms of trial and error studies and sample applications, it can be said that the hemming force applied should be between $60-100 \mathrm{daN}$ for a motor hood outer plate with a thickness of $0,8 \mathrm{~mm}$ [9].

In the robotic roller hemming method, edge bending is performed in three steps. Between steps, the angular position changes of the cylinder are made by the robot through a computer software running on the backplane. These steps are performed sequentially. First, the bending process is performed up to 90 degrees. It is then rolled up to 135 degrees [9]. The last operation is the clamping operation, which is done up to 180 degrees. All these operations are done quickly with support of computer software. Depending on the development of the technology, the error rate is reduced.

\section{Hemming Process Apply}

This section of the main stages of a suitable robotic roller hemming process the requested production capacity of 1 annually to companies engaged in production in the automotive industry will be examined. The data used in the process development is predictive. System parameters as product identification tools are the front doors left and right side door). Products are determined on an annual basis to 10,000 units. For working time for the year; two shifts, 280 working days and yields $80 \%$.

The amount foreseen for robotic production cells, which will be designed to be combined with the hemming method is suitable. Panel installation is done by the operator. However, mastic, marriage, the left panel to the exit conveyor after hemming and hemming process is performed in robotic applications. Estimated size of hemming the 4000 bond mastic size $4000 \mathrm{~mm}$ and $2500 \mathrm{~mm}$ anti-flout will be accepted.

The panel on the outlet conveyor is moved by the operator to the dock area. All cell time analysis on this data is prepared and placement process flow diagram.

Based on these data when determine cell cycle time calculation shows availability for a vehicle manufactured in 564.48 seconds. This calculation will reduce the rate of production than data and predict it will stop producing state have been overlooked. It shows the general layout of the equipment in the production cell designed (Figure 3 ).

\section{Conclusion}

Compared to die hemming and hemming table top application is a more economical method in terms of initial investment cost and process efficiency. In terms of processing time is a slower process compared to other methods is therefore not a suitable choice in high capacity production. Cells used in the process equipment can continue to be used again in different places at the end of the target production process. For example; industrial robots can be divided to be used in another process, roller hemming head twisting forms may continue to be used in other projects as long as it is convenient.

Die hemming and table-top methods, although not economical in terms of initial investment cost, in terms of process efficiency and faster processing times. Therefore, they are preferred in high-capacity production. At the end of the targeted production time due to special machine design part it is not suitable for evaluation should be performed in different projects.

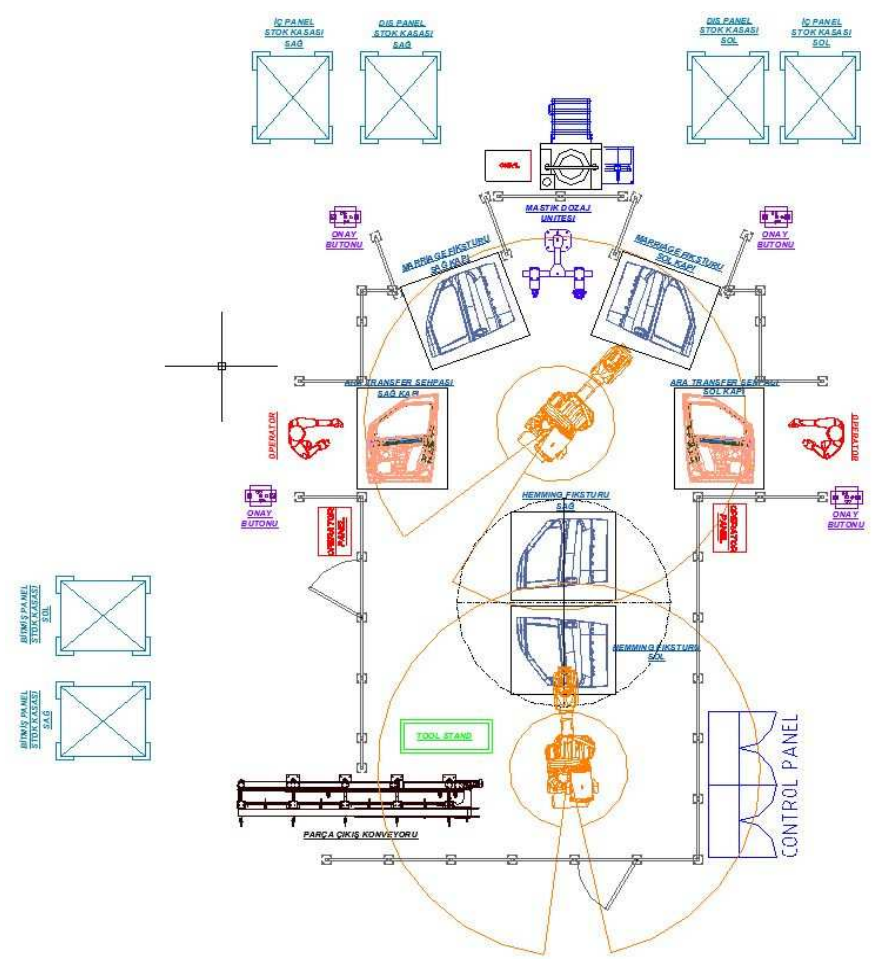

Figure 3. Production cell organization. 


\section{References}

[1] US5587042, E. R. St. Denis-Sons Ltd., Adhesive curing system and method for a hemming machine, (1995).

[2] P. W. Bridgeman, P. W., Studies in large plastic flow and fracture, Harvard University Press, Cambridge, MA (1964), pp. 38-86.

[3] Denis, Lucen St. "Hemming machine and method." U. S. Patent No. 5,150,508. 29 Sep. 1992.

[4] Adamski Jr, Maximilian, Robert E. Smith, and Dhimat R. Desai. "Method and apparatus for hemming." U. S. Patent No. 4,098,201. 4 Jul. 1978.

[5] Letard, Michel, and Daniel Renouvin. "Apparatus for automatically hemming tubular garments on a sewing machine.” U. S. Patent No. 4,473,017. 25 Sep. 1984.

[6] Duflou, J. R. and others, Methods for the sequencing of sheet metal bending operations, International Journal of Production Research, 37 (14),1999, 3185-3202.

[7] Cattrysse, D. And other, "Automatic production planning of press brakes for sheet metal bending" International Journal of Production Research, 2006, 44:20, 4311-4327.

[8] Rico, J. C. And others, "Automatic determination of bending sequences for sheet metal parts with parallel bends" International Journal of Production Research, 2003 41:14, pages 3273-3299.

[9] Www.essay.utwente.nl/58315/1/graduate_bjonkers.pdf.

[10] Livatyal1, H. And others, "Improvement of hem quality by optimizing flanging and pre-hemming operations using computer aided die design" Journal of Materials Processing Technology98 (1) 2000, 41-52.

[11] Muderrisoglu, A., "Bending, flanging and hemming of sheet an experimental study" J. Mater. Proc. Technol., 59 (1996), pp. $10-17$.

[12] Wanintradul, C. and other, "Hemming process with counteraction force to prevent creepage" Journal of Manufacturing Processes, 16 (3), 2014, 379-390.

[13] Lin, G. And other, "A computational design of experiments study of hemming processes for automotive aluminium alloys” J Eng. Manuf, 219 (2005), 711-722.

[14] Http://www.autoform.com/en/glossary/hemming/. 